\title{
Method of verifying the emission level of the exhaust components of a special vehicle in relation to EURO III standard in road conditions
}

\section{ARTICLE INFO}

Received: 16 September 202

Revised: 19 October 2021

Accepted: 30 October 2021

Available online: 2 November 2021
The following article presents the method of verification of EURO III standard in real conditions for special vehicles. The test object qualified as a special vehicle was tested in road conditions along a defined route, and then the obtained measurement results were compared to the exhaust emission standard (EURO III) applicable for this vehicle. A method of comparing the emission factors in road conditions with the indicators obtained on the engine dynamometer was proposed. An AVL mobile exhaust gas analyzers PEMS dedicated for RDE road tests were used in the research.

Key words: emissions verification method, PEMS, special vehicle, RDE, exhaust components

This is an open access article under the CC BY license (http://creativecommons.org/licenses/BY/4.0/)

\section{Introduction}

Air pollution, and in consequence the health problem gains greater importance every year. The subsequent EURO standards, which describes the allowable limits of exhaust gases emission are even more stringent $[1,2]$. It was found that nowadays real-world emissions exceed the level achieved in the laboratory tests, especially the emission of nitrogen oxides emitted by diesel engines. Therefore, the usability of the road test is proposed [1,3-5].

The vehicles are investigated according to accurate methods using a variety of sophisticated devices. One of the most common and accurate methods of exhaust gases verification is Portable Emission Measurement System (PEMS). The models developed based on PEMS measurements are widely used to predict the pollution in an urban area which helps to select the perfect location of urban facilities such as, for example pedestrian crossings [5]. It was also determined that the most hazardous emission is generated while accelerating from 0 to $80 \mathrm{~km} / \mathrm{h}$ [6].

In general, PEMS methodology is predominantly applicable for gaseous emission only. Lately, it was also introduced to the heavy-duty vehicle due to the implementation of solid particle number (PN). The performance of the heavy-duty vehicles was verified and the result was described in [7]. It appeared that the results are within 40$65 \%$ of the laboratory standards with only minor robustness issues, which makes them suitable for in-service conformity regulation.

The EURO III standard requires the performance of an experiment in a strict regime, mostly with the aid of a dynamometer. In consequence to verify the compliance of and existing vehicle with this standard, it is required to dismount the engine and perform investigations. The PEMS systems provide the possibility to perform the euro test in real-time driving. All parameters of the exhaust gases are gathered during road tests [5]. However, in the case of road test the reliable and repeatable conditions are much more difficult to achieve. The style of driving can affect the measurements. As it was proven in [8] the emission characteristic depends on the type of traffic flow. Therefore, the change in driving behaviour, or driving gear selection leads to a significant increase of emission factor. Moreover, the traffic is a determining factor in creating $\mathrm{NO}_{\mathrm{x}}$ pollutants [9]. It was also found that the emission factor depends not only on the driving operational intensity but also on the duration and frequencies of individual maneuver states. Another important factor in the emission problems is the aging of vehicles. It appears that even fivefold growth of $\mathrm{CO}$ and $\mathrm{HC}$ was determined for vehicles older than 15 years [1].

Since the year 2020 the conformity factor for new vehicles is 1.5 . No matter the difficulty to provide repeatable test results, it is planned to implement the RDE with PEMS measurements for legislation approval [10]. However, the vast amount of factors affecting the RDE test (e.g. traffic, driving behaviour, moisture, ambient pressure and temperature, etc.) should be taken into account. It is speculated that this should be overcome by focusing on the most frequently driven operating conditions $[11,12]$.

This paper provides an overview of the possibility to implement the PEMS measurement for heavy-duty special vehicle compliance with EURO III standards. The authors are aware of the inaccuracy of the method, which in its assumptions does not use the OBD system, but their main goal was to propose a method suitable for use on a military vehicle in road conditions without connection to diagnostic systems.

\section{Methodology}

\subsection{Test vehicle}

Vehicle that was an object of investigation (Fig. 1) was classified as N3G group according to the EU type approval system. It is dedicated to carrying goods for military purposes in off-road conditions, thus it is treated as a special purpose vehicle and it is not obliged to fulfill corresponding emissions requirements for commercial heavy-duty trucks.

Due to the limited maximum speed of the test vehicle (Table 1), it was impossible to implement an ETC chassis dynamometer test suitable for the EURO III engine, where the average speed of the motorway part is set at a level of 
$88 \mathrm{~km} / \mathrm{h}$. Moreover, the design of the vehicle with three driving axles makes it practically impossible to test on a standard chassis dynamometer.

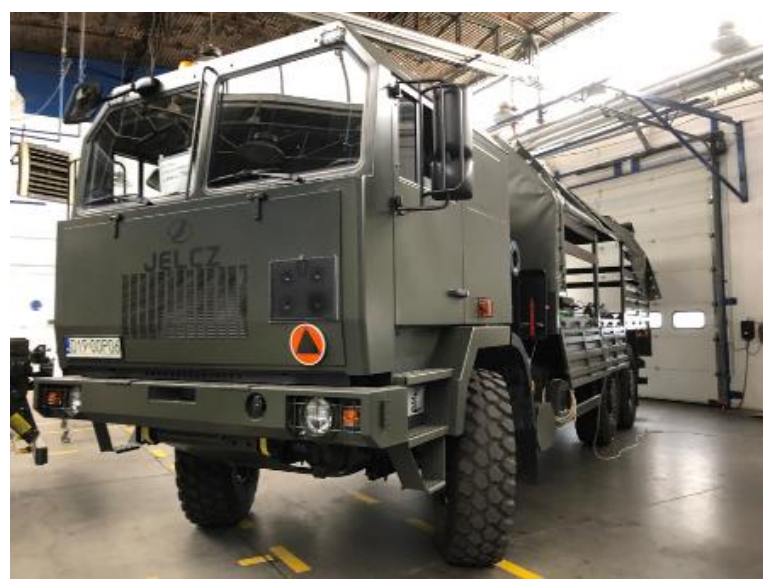

Fig. 1. Test vehicle

Table 1. Selected parameters of the test vehicle

\begin{tabular}{|l|c|}
\hline Category & $\mathrm{N} 3 \mathrm{G}$ \\
\hline Mileage & $321 \mathrm{~km}$ \\
\hline Engine type & Compression ignition, turbocharged \\
\hline Engine displacement & $10300 \mathrm{ccm}$ \\
\hline Max. power & $316 \mathrm{~kW}$ at $2100 \mathrm{RPM}$ \\
\hline Max. velocity & $85 \mathrm{~km} / \mathrm{h}$ \\
\hline Emissions standard & EURO III \\
\hline Vehicle curb weight & $12200 \mathrm{~kg}$ \\
\hline Permissible gross weight & $27000 \mathrm{~kg}$ \\
\hline Tires & $14 \mathrm{R} 20 \mathrm{~A} / \mathrm{T}$ \\
\hline
\end{tabular}

\subsection{Measuring equipment}

Vehicle tailpipe emissions measurement was conducted with an AVL PEMS system dedicated to RDE testing consisting of the following components:

- GAS module equipped with two channel FID enabling simultaneous measurement of THC and $\mathrm{CH}_{4}, \mathrm{NIDR}$ analyzer for $\mathrm{CO}_{2}$ and $\mathrm{CO}$ reading, NDUV unit for $\mathrm{NO}_{x}$ measurement and paramagnetic analyzer for $\mathrm{O}_{2}$ measurement,

- PM module composed of measuring unit equipped with a laser NDIR meter capable of continuous measurement of PM quantity and gravimetric filter for recording particulate mass,

- EFM device based on Pitot tubes enabling exhaust gases flow measurement even in case of relatively strong pulsations while the engine is idle or highly loaded. For purposes of the following research, a 4 inches diameter flowmeter was used,

- SC module dedicated to recording and processing of all signals with $2 \mathrm{~Hz}$ frequency,

- GPS unit for measuring vehicle ground velocity independently from its instruments, capable of connecting with up to 12 satellites at the same time,

- weather station collecting data about ambient pressure and temperature,

- batteries providing independent source of power for all measuring devices,

- generator being a backup source of energy in case of batteries failure.

\subsection{Testing procedure}

Due to the fact that the tested vehicle was designed to carry loads, most of the measuring devices were installed on the cargo area on its back as shown in Fig. 2. The weather station, as well as GPS unit were placed on the roof to increase the accuracy of the measurements. The full test should consist of at least two runs, first without payload and second with 50 to $60 \%$ of the maximum vehicle payload. Such requirements result from differences in driving characteristics of an off-road vehicle [13].

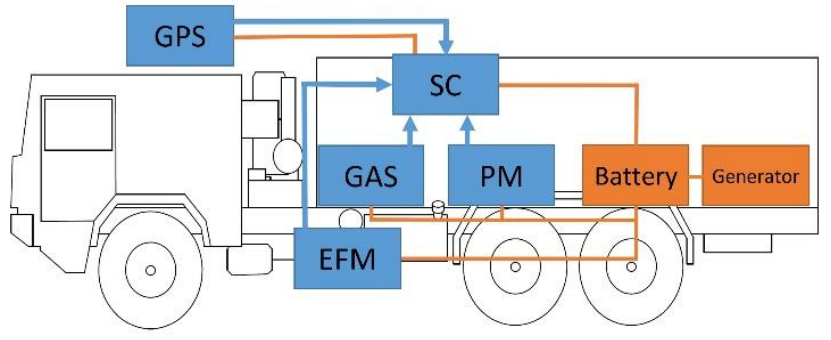

Fig. 2. Scheme of equipment setup

Before the test tire pressure was adjusted according to the manufacturer's data and a test drive was conducted to achieve the operating temperature of an engine and check all the readings.

The tests were carried out on a route defined by the Military Technological Guide developed in compliance with the Polish Defense Department requirements. The test circuit was established over a total distance of $22.5 \mathrm{~km}$ in both directions.

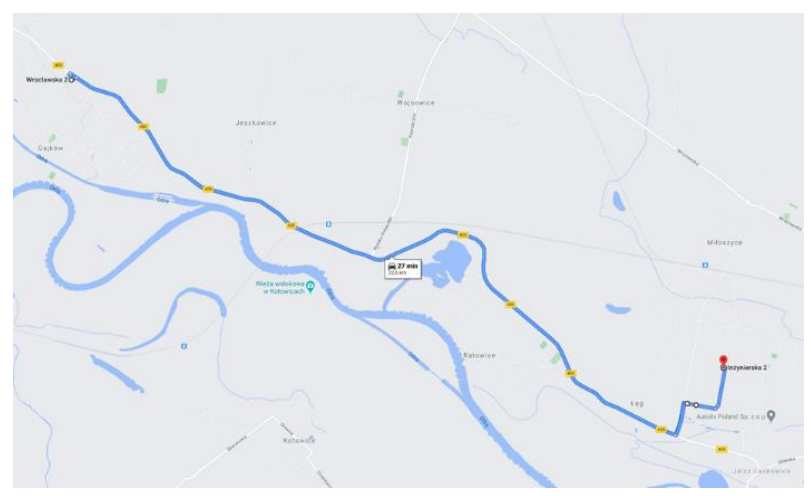

Fig. 3. Test route

The test route was established to minimize the influence of congestion and ambient conditions on the test results.

\subsection{Method description}

Before calculating vehicle energy demand, a fuel sample needs to be tested to determine the calorific value necessary for further analysis. The calorific value of the fuel sample is determined according to the reference method described by the norm PN-Z-15008-4:1993. Then the engine emission factors of the vehicle are calculated from the actual values during the test. The total fuel consumption for the test was calculated using the airflow and air to fuel ratio measurement method described in detail by the formulas in section 8.4.1.6 of Annex 4 to UN/ECE Regulation No 49. 
Thanks to the PEMS SC unit, this part of the research was automated, so the total masses of particular components and the fuel consumed were known.

The mentioned method being similar to the carbon balance method, is based on the assumption that the total mass of carbon in the fuel consumed is equal to the total carbon mass in the exhaust gases. Today fuels are composed almost only of saturated hydrocarbons; thus during the combustion process all carbon molecules are emitted in exhaust gases.

To estimate the total carbon mass of exhaust gases the concentrations of $\mathrm{CO}, \mathrm{CO}_{2}$ and $\mathrm{THC}$ have to be measured. Moreover, an air to fuel ratio measurement equipment such as a zirconia type sensor is used for the measurement of the excess air ratio.

The selection of airflow and air to fuel ratio measurement method over the carbon balance method resulted from the fact that it does not require any of the ECU readings, making it more objective and suitable to use when an engine is not equipped with any sensors.

The next step of the evaluation method proposed by the authors is the calculation of the total energy consumption in the road test, which is done according to formula 1 .

$$
\mathrm{E}_{\mathrm{T}}=\mathrm{m}_{\mathrm{f}} * \mathrm{c}_{\mathrm{f}}
$$

where: $\mathrm{E}_{\mathrm{T}}-$ is total energy consumption in test, $[\mathrm{MJ}], \mathrm{m}_{\mathrm{f}}-$ is total mass of fuel consumed, $[\mathrm{kg}], \mathrm{c}_{\mathrm{f}}-$ is fuel calorific value, $[\mathrm{MJ} / \mathrm{kg}]$.

Since energy consumption can be straightforwardly converted into $\mathrm{kWh}$ unit the emission per $\mathrm{km}$ for any exhaust component may now be calculated.

$$
\mathrm{m}_{\mathrm{x}}=\mathrm{m}_{\mathrm{xT}} / \mathrm{E}_{\mathrm{T}}
$$

where: $m_{x}-$ is specific emission of component, [g/kWh], $\mathrm{m}_{\mathrm{xT}}-$ is total mass of component emitted in test, $[\mathrm{g}], \mathrm{E}_{\mathrm{T}}$, is total energy consumption in test, [kWh].

The last step in the assessment of vehicle emissions is the comparison of the values obtained with the emission limits specified by the EURO III standard. Due to the experiment character, limits for transient testing should be applied. They are presented in the Table 2.

Table 2. Emission limits for heavy-duty CI engines - transient testing [14]

\begin{tabular}{|c|cc|}
\hline Exhaust component & \multicolumn{2}{|c|}{ Limit } \\
\hline $\mathrm{CO}$ & 5.45 & $\mathrm{~g} / \mathrm{kWh}$ \\
\hline $\mathrm{NMHC}$ & 0.78 & $\mathrm{~g} / \mathrm{kWh}$ \\
\hline $\mathrm{CH}_{4}$ & 1.60 & $\mathrm{~g} / \mathrm{kWh}$ \\
\hline $\mathrm{NO}_{\mathrm{x}}$ & 5.00 & $\mathrm{~g} / \mathrm{kWh}$ \\
\hline $\mathrm{PM}$ & 0.16 & $\mathrm{~g} / \mathrm{kWh}$ \\
\hline
\end{tabular}

\section{Results}

The road test was conducted under moderate traffic conditions. The average ambient temperature during the test was $20.8^{\circ} \mathrm{C}$ with a relative humidity of $46 \%$. The duration of the test was about 36 minutes with an average velocity of $37.05 \mathrm{~km} / \mathrm{h}$.

The course of the speed profile clearly shows that the route will be driven in both directions at a similar speed.

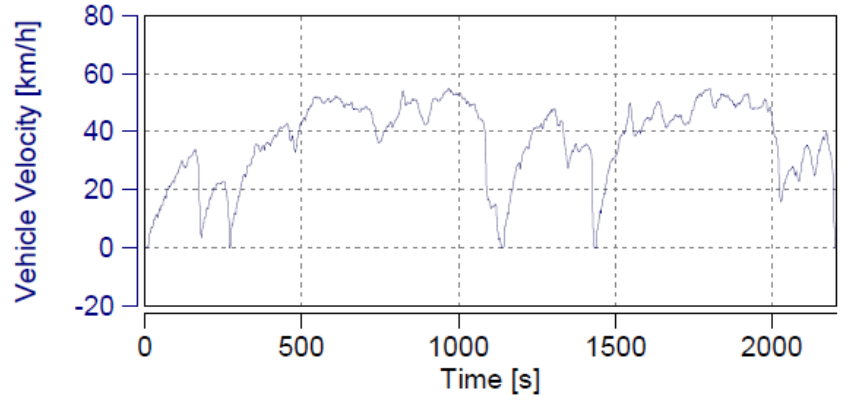

Fig. 4. Road test velocity profile of the vehicle

The concentrations of the selected exhaust components in the road test were recorded and presented in a graphical form.

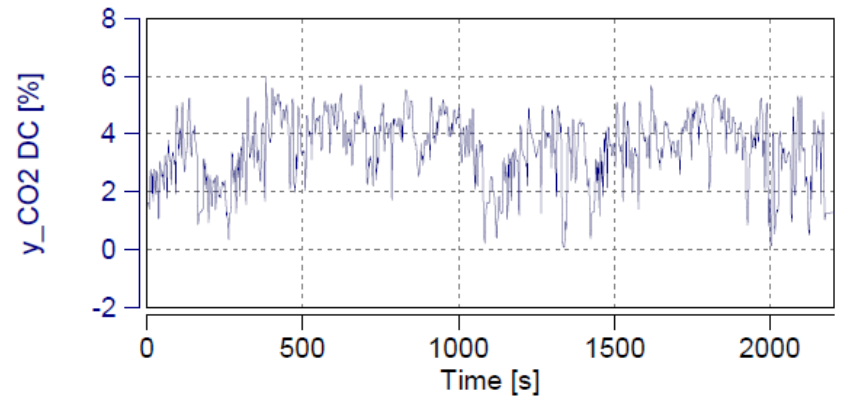

Fig. 5. Carbon dioxide concentration during the test

In the case of the course of carbon dioxide emission, a clear correlation was observed with the vehicle speed profile during the test. At the same time, it was discovered that the oxygen concentration curve is an inverse of the carbon dioxide curve, which was expected.

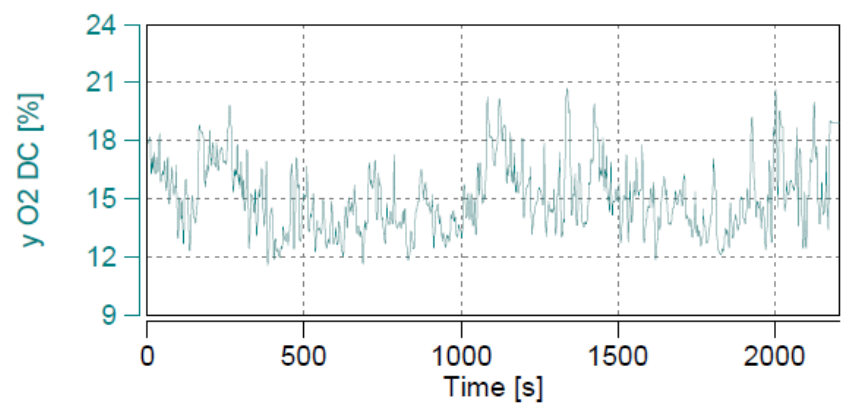

Fig. 6. Oxygen concentration during the test

The concentration of oxygen in the exhaust gas reaches its highest values during stops and engine braking.

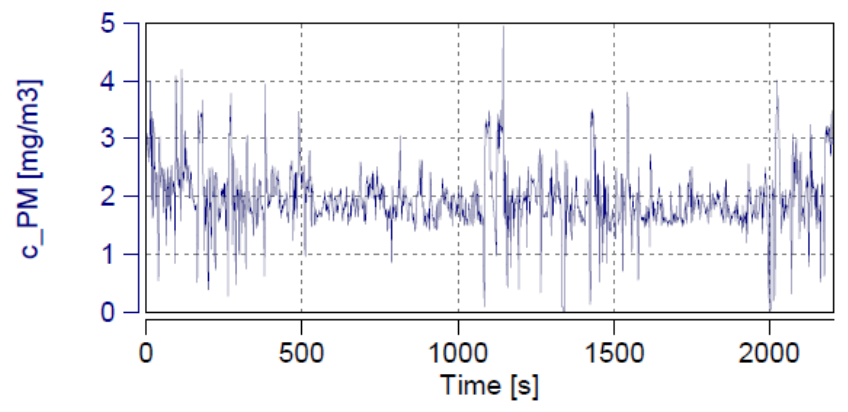

Fig. 7. Particulate matter concentration during the test 
The highest concentration of particulate matter during the test was observed during the acceleration of the vehicle. It was connected with an increase in fuel consumption under those conditions resulting from a rapid increase in engine load.

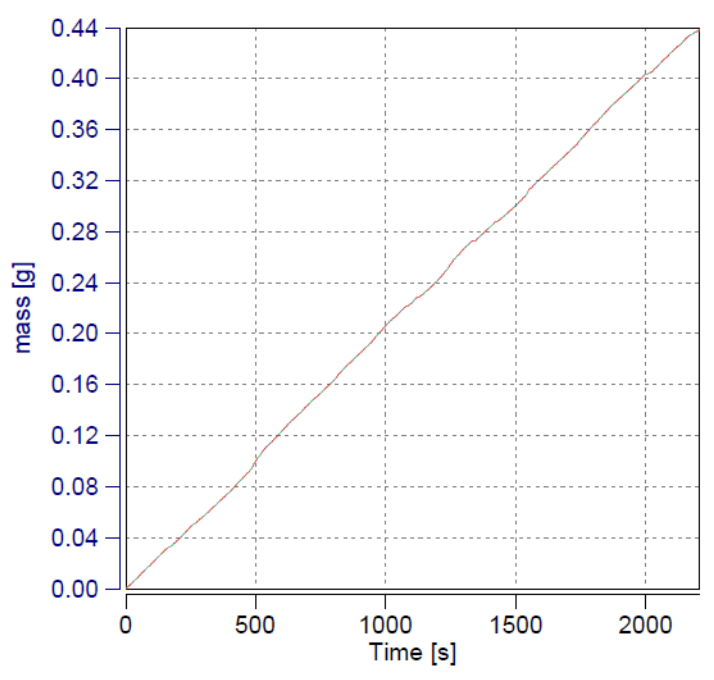

Fig. 8. Particulate mass during the test

The progression of the total amount of particulate mass, similar to the linear one, proves that the test was performed correctly and the route was properly selected.

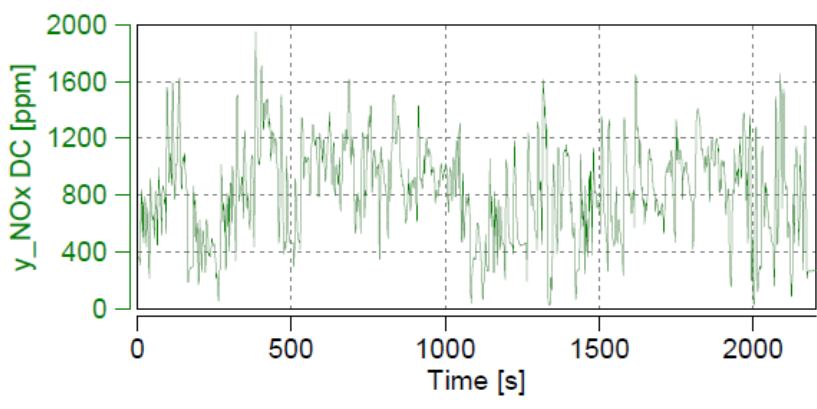

Fig. 9. Nitrogen oxides concentration during the test

The highest concentration of nitrogen oxides was observed during engine load, as is the case with carbon dioxide. The increase in the amount of nitrogen oxides is related to the increase in the temperature of the combustion process; therefore, it proves that the engine was working properly.

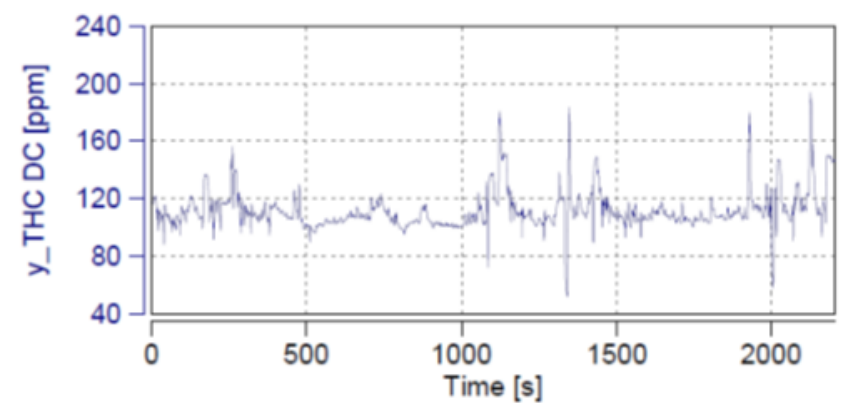

Fig. 10. Total hydrocarbons concentration during the test
For most of the test, the hydrocarbon concentration fluctuated around a constant value of $100 \mathrm{ppm}$. Visible peaks were observed while the vehicle decelerated. The increase in hydrocarbons during engine braking is a natural symptom of its work.

All of the courses obtained did not differ from the expected values. The characteristics of the concentrations of the individual components did not show any abnormalities in the engine operation during the test and were used for further analysis.

The calorific value of the fuel was determined (Table 3) and the calculated mass of the fuel consumed was referred to its calorific value, thus obtaining the total energy consumption in the test.

Table 3. Road test data
\begin{tabular}{|l|c|c|}
\hline Duration & 2205 & $\mathrm{~s}$ \\
\hline Distance & 22.8 & $\mathrm{~km}$ \\
\hline Average velocity & 37.2245 & $\mathrm{~km} / \mathrm{h}$ \\
\hline Consumed fuel mass & 5.24 & $\mathrm{~kg}$ \\
\hline Fuel calorific value & 47.57 & $\mathrm{MJ} / \mathrm{kg}$ \\
\hline Total energy consumption & 249.267 & $\mathrm{MJ}$ \\
\hline Specific energy consumption & 10.9328 & $\mathrm{MJ} / \mathrm{km}$ \\
\hline
\end{tabular}

The total emitted mass of the compounds was calculated and then the emission factors were obtained by relating the mass of the compounds to the distance traveled.

Table 4. Selected engine emission factors in test

\begin{tabular}{|l|cc|cc|cc|}
\hline \multirow{2}{*}{$\begin{array}{c}\text { Exhaust } \\
\text { component }\end{array}$} & $\begin{array}{c}\text { Total mass } \\
\text { emitted in } \\
\text { test }\end{array}$ & \multicolumn{2}{c|}{$\begin{array}{c}\text { Emission per } \\
\mathrm{km}\end{array}$} & \multicolumn{2}{|c|}{$\begin{array}{c}\text { Emission per } \\
\mathrm{kWh}\end{array}$} \\
\hline $\mathrm{THC}$ & 15.58 & $\mathrm{~g}$ & 0.68 & $\mathrm{~g} / \mathrm{km}$ & 0.225 & $\mathrm{~g} / \mathrm{kWh}$ \\
\hline $\mathrm{NMHC}$ & 15.27 & $\mathrm{~g}$ & 0.67 & $\mathrm{~g} / \mathrm{km}$ & 0.220 & $\mathrm{~g} / \mathrm{kWh}$ \\
\hline $\mathrm{CH}_{4}$ & 0.36 & $\mathrm{~g}$ & 0.02 & $\mathrm{~g} / \mathrm{km}$ & 0.005 & $\mathrm{~g} / \mathrm{kWh}$ \\
\hline $\mathrm{CO}_{2}$ & 16352.80 & $\mathrm{~g}$ & 717.23 & $\mathrm{~g} / \mathrm{km}$ & 235.984 & $\mathrm{~g} / \mathrm{kWh}$ \\
\hline $\mathrm{NO}$ & 370.01 & $\mathrm{~g}$ & 16.23 & $\mathrm{~g} / \mathrm{km}$ & 5.340 & $\mathrm{~g} / \mathrm{kWh}$ \\
\hline $\mathrm{NO}_{2}$ & 25.12 & $\mathrm{~g}$ & 1.10 & $\mathrm{~g} / \mathrm{km}$ & 0.362 & $\mathrm{~g} / \mathrm{kWh}$ \\
\hline $\mathrm{NO}_{\mathrm{x}}$ & 395.13 & $\mathrm{~g}$ & 17.33 & $\mathrm{~g} / \mathrm{km}$ & 5.707 & $\mathrm{~g} / \mathrm{kWh}$ \\
\hline $\mathrm{PM}$ & 4.38 & $\mathrm{~g}$ & 0.19 & $\mathrm{~g} / \mathrm{km}$ & 0.063 & $\mathrm{~g} / \mathrm{kWh}$ \\
\hline
\end{tabular}

\section{Discussion}

The results obtained (Table 4) in relation to the emission limits (Table 2) indicate that the EURO III standard was met in relation to non-methane hydrocarbons, methane and particulate mass. In the case of nitrogen oxides, the limit was exceeded, thus further testing with payload was stopped.

As it was mentioned in paragraph 2.4 , the undoubted advantage of the presented method is its versatility and the possibility of testing independently from the sensors in the vehicle. The methodology presented in this article, in relation to the reference method for the verification of EURO III emission factors, allows the vehicle to be tested in conditions similar to its natural road operation. For further verification of the method, consecutive tests are required with the vehicle operating in terrain conditions.

The test route should be selected in such a way that it is possible to achieve an average speed approximately $50 \%$ of the maximum speed of the vehicle. The complete test should consist of a route in both directions to minimize the influence of congestion and ambient conditions on the test results. 


\section{Acknowledgements}

Testing equipment used in the presented research was purchased by Wrocław University of Science and Technology as a part of the "Complex GEO-3EM ENERGY ECOLOGY EDUCATION" financed by the European
Regional Development Fund within the Regional Operational Program of the Lower Silesian Voivodship for the years 2014-2020.

\section{Nomenclature}

AVL Anstalt für Verbrennungskraftmaschinen List

ECE Economic Commission for Europe

ECU engine control unit

EFM electronic flow meter

ETC European transient cycle

EU European Union

FID flame ionization detector

GPS global positioning system

NDIR nondispersive infrared
NDUV non-dispersive ultra violet spectroscopy

NMHC non-methane hydrocarbons

PEMS portable emission measuring system

PM particulate mass

PN particulate number

$\mathrm{RDE}$ real driving emissions

SC system control

THC total hydrocarbons

UN United Nations

\section{Bibliography}

[1] HASSANI, A., SAFAVI, S.R., HOSSEINI, V. A comparison of light-duty vehicles' high emitters fractions obtained from an emission remote sensing campaign and emission inspection program for policy recommendation. Environmental Pollution. 2021, 286, 117396.

https://doi.org/10.1016/j.envpol.2021.117396

[2] PUŠKÁR, M., KOPAS, M. System based on thermal control of the HCCI technology developed for reduction of the vehicle $\mathrm{NO}_{\mathrm{x}}$ emissions in order to fulfil the future standard $\mathrm{Eu}$ ro 7. Science of the Total Environment. 2018, 643, 674-680. https://doi.org/10.1016/j.scitotenv.2018.06.082

[3] LUJÁN, J., BERMÚDEZ, V., DOLZ, V. et al. An assessment of the real-world driving gaseous emissions from a Euro 6 light-duty diesel vehicle using a portable emissions measurement system (PEMS). Atmospheric Environment. 2018, 174, 112-121.

https://doi.org/10.1016/j.atmosenv.2017.11.056

[4] KO, J., JIN, D., JANG, W. et al. Comparative investigation of $\mathrm{NO}_{\mathrm{x}}$ emission characteristics from a Euro 6-compliant diesel passenger car over the NEDC and WLTC at various ambient temperatures. Applied Energy. 2017, 187, 652-662. https://doi.org/10.1016/j.apenergy.2016.11.105

[5] JAWORSKI, A., MĄDZIEL, M., LEJDA, K. Creating an emission model based on portable emission measurement system for the purpose of a roundabout. Environmental Science and Pollution Research. 2019, 26. https://doi.org/10.1007/s11356-019-05264-1

[6] SÖDERENA, P., LAURIKKO, J., WEBER, C. et al. Monitoring Euro 6 diesel passenger cars $\mathrm{NO}_{\mathrm{x}}$ emissions for one year in various ambient conditions with PEMS and $\mathrm{NO}_{\mathrm{x}}$ sensors. Science of the Total Environment. 2020, 746, 140971. https://doi.org/10.1016/j.scitotenv.2020.140971

[7] GIECHASKIEL, B., SCHWELBERGER, M., DELACROIX, C. et al. Experimental assessment of solid particle

Prof. Andrzej R. Kaźmierczak, DSc., DEng. - Faculty of Mechanical Engineering, Wrocław University of Science and Technology.

e-mail: andrzej.kazmierczak@pwr.edu.pl number Portable Emissions Measurement Systems (PEMS) for heavy-duty vehicles applications. Journal of Aerosol Science. 2018, 123, 161-170.

https://doi.org/10.1016/j.jaerosci.2018.06.014

[8] YU, Q., YANG, Y., XIONG, X. et al. Assessing the impact of multi-dimensional driving behaviors on link-level emissions based on a Portable Emission Measurement System (PEMS). Atmospheric Pollution Research. 2021, 12(1), 414424. https://doi.org/10.1016/j.apr.2020.09.022

[9] GÓMEZ, A., FERNÁNDEZ-YÁÑEZ, P., SORIANO, J.A. et al. Comparison of real driving emissions from Euro VI buses with diesel and compressed natural gas fuels. Fuel. 2021, 289, 119836. https://doi.org/10.1016/j.fuel.2020.119836

[10] OLABI, A.G., MAIZAK, D., WILBERFORCE, T. Review of the regulations and techniques to eliminate toxic emissions from diesel engine cars. Science of the Total Environment. 2020, 748, 141249 .

https://doi.org/10.1016/J.SCITOTENV.2020.141249

[11] LEE, T., PARK, J., KWON, S. et al. Variability in operationbased $\mathrm{NO}(\mathrm{x})$ emission factors with different test routes, and its effects on the real-driving emissions of light diesel vehicles. The Science of the Total Environment. 2013, 461-462, 377-385. https://doi.org/10.1016/j.scitotenv.2013.05.015

[12] MERKISZ, J., RYMANIAK, Ł., ZIÓŁKOWSKI, A. et al. The analysis of the emission level from a heavy-duty truck in city traffic. Combustion Engines. 2012, 150(3), 80-88. https://doi.org/10.19206/CE-117033

[13] MERKISZ, J., PIELECHA, J., STOJECKI, A. et al. The influence of terrain topography on vehicle energy intensity and engine operating conditions. Combustion Engines. 2015, 162(3), 341-349.

[14] Directive 1999/96/EC of the European Parliament and of the Council.
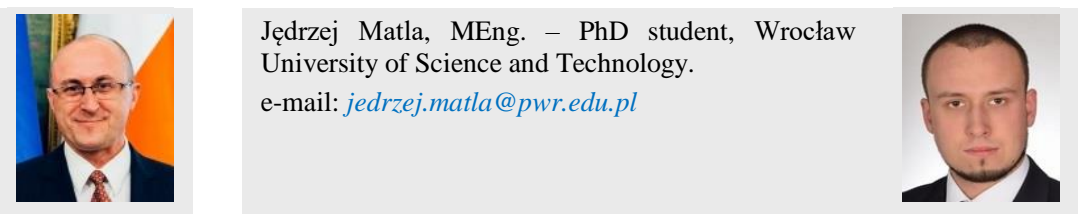